\title{
O deus silencioso na poesia de Ana Marques Gastão
}

Resumo: A coletânea de poemas $O$ silêncio de deus, da poeta portuguesa Ana Marques Gastão, constitui uma parte do livro Três vežes Deus (2001), publicado em co-autoria com António Rego Chaves e Armando Silva Carvalho, e também compõe a antologia $A$ definição da noite, lançada no Brasil em 2003. Esse núcleo de poemas é revelador do sagrado na poesia da citada poeta cujo veio se fundamenta na constatação de um deus, em letra minúscula, silencioso, mudo e, por vezes, ausente, que, ainda assim, é buscado pelo eu lírico. Diante disso, pretende-se aqui perscrutar o sagrado na poesia de Ana Marques Gastão, tendo como objeto de análise os poemas da citada coletânea. A base teórica é composta por Mircea Eliade (2010), Octavio Paz (1982), Nelson de Oliveira (2009) e alguns ensaios.

Palavras-chave: poesia; sagrado; Ana Marques Gastão.

Abstract: The collection of poems O silêncio de deus, by portuguese poet Ana Marques Gastão, is a part of the book Três vezes Deus (2001), published in co-authorship with António Rego Chaves and Armando Silva Carvalho, and it also composes the anthology A definição da noite, thrown in Brazil in 2003. This core revealing of the poet's sacred poetry whose came is based on finding a god, in lower case, silent, silent and sometimes missing, still, is sought by the lyric. In front of that, $\mathrm{t}$ is intended here consult the sacred poetry of Ana Marques Gaston, having as object of analysis the poems of this collection. The theoretical basis is composed by Mircea Eliade (2010), Octavio Paz (1982), Nelson de Oliveira (2009) and some essays.

Key-words: poetry; sacred; Ana Marques Gastão.

\section{Introdução}

Nas palavras de Carlos Nejar proferidas no prefácio da antologia $A$ definição da noite (2003), Ana Marques Gastão é “"...] uma voz original e vigorosa na atual poesia portuguesa contemporânea. [...] autora de quatro livros publicados, com sucesso de público e crítica" (NEJAR In: GASTÃO, 2003, p. 7). Tendo isso em vista, antes de adentrarmos no estudo da poesia desta poeta, é pertinente que nos reportemos brevemente à sua vida, uma vez que sua trajetória literária é recente, mas intensa.

Ana Marques Gastão nasceu em Lisboa, Portugal, no ano de 1962. É poeta, crítica literária, ensaísta. Coordena a revista Colóquio-Letras da Fundação Gulbenkian desde 2009. É advogada, licenciada em Direito pela Universidade Católica Portuguesa. Durante mais de vinte anos, foi jornalista cultural. Além disso, foi crítica de artes plásticas e crítica de dança. Publicou Tempo de morrer, Tempo para viver (1998), Terra sem mãe (2000), Três vežes Deus, em co-

\footnotetext{
${ }^{1}$ Mestranda em Letras - Estudos Literários, pelo Programa de Pós-Graduação em Letras da Universidade Federal do Amazonas - UFAM. Membro do Grupo de Estudos e Pesquisas em Literaturas de Língua Portuguesa - GEPELIP. Bolsista CAPES. E-mail: aleite.kal@gmail.com
} 
autoria com António Rego Chaves e Armando Silva Carvalho (2001), Nocturnos (2002), Nós/Nudos, 25 poemas sobre imagens de Paula Rego, publicado na França, traduzido para o castelhano e ganhador do Prémio Pen Clube 2004, e Lápis mínimo (2008). A antologia A definição da noite foi editada no Brasil em 2003. Em 2011, publicou Adornos pela editora Dom Quixote. Lançou em maio deste ano no Brasil, em conjunto com Sérgio Nazar David, o livro O olho e a mão (2018) pela editora 7 Letras, no Rio de Janeiro.

A produção poética de Ana Marques Gastão é já profundamente intensa, motivo mais do que suficiente para que sejam realizados estudos aprofundados sobre sua poesia. Assim, pretendemos neste artigo perscrutar o sagrado em $O$ silêncio de deus a partir da análise de alguns poemas para revelarmos a presença desta temática na poesia de Ana Marques Gastão.

\section{Três vozes poéticas para falar de Deus}

A coletânea de poemas O silêncio de deus integra a obra Três vežes Deus, publicada conjuntamente com António Rego Chaves e Armando Silva Carvalho, em 2001. São três poetas que, de acordo com Manuel António Ribeiro, constituem "vozes distantes que transportam para o interior dos versos o problema de Deus, não com formulações categóricas, mas como quem balbucia procuras, sem se esquivar aos incómodos inerentes à equação deste insondável mistério." (RIBEIRO, 2008, p. 25). Nesse sentido, há uma particularidade na forma como cada poeta escreve seus poemas a respeito de Deus. Pormenorizando a coletânea de cada autor, Ribeiro inicia tratando de $\mathrm{O}$ silêncio de deus, a primeira, de autoria de Ana Marques Gastão, salientando que o silêncio problematizado nos versos dos poemas "tanto pode sugerir a sombra de sentido como traduzir a busca de uma verdadeira significação" (RIBEIRO, 2008, p. 25), pois o silêncio, comprovadamente, desperta em nós reflexões e indagações que exigem uma verdade ou uma resposta na medida em que é o instante no qual há uma tentativa de apreensão e de compreensão de algo ou alguém distante de nós.

$\mathrm{Na}$ composição dos poemas de $O$ silêncio de deus, notamos a profundidade da reflexão filosófica a respeito de um deus, grafado em letra minúscula, no qual frequentemente depositam-se dúvidas, incertezas, porque a compreensão do divino nos foge em nossa realidade humana distante, às vezes, do sagrado e, por vezes, inserida no profano. Tal filosofia poética sobre deus acalenta também a espera, a crença, ora iluminada ora obscurecida, e a presença velada do divino que ampara e guia.

Ao falar sobre a poesia de Ana Marques Gastão, Carlos Nejar pontua que "há uma ferocidade que não se dá tréguas no tratamento dos temas e na crueza de sua afirmação. $\mathrm{O}$ que se designa, abre-se em botão numa linguagem que não cede aos facilismos" (NEJAR In: GASTÃO, 2003, p. 7). Observa-se tal ferocidade poética ao falar acerca de um deus que se silencia e permanece mudo ao longo da vida, afirmando seu destemor como poeta que escreve sem aceitar "a submissão omissa do silêncio" (Idem, 2003, p. 7).

A poeta escreve "balbuciando procuras" (RIBEIRO, 2008, p. 25) porque deus está ausente em sua presença. A coletânea citada contém poemas que seguem uma ordem alfabética, intitulados cada um com uma letra do alfabeto. Ribeiro esclarece que tal ordenamento se configura como uma “[...] contagem, cujo arrumo artificial não será inocente, sugere o ressumar dos versículos do Apocalipse que nos apresentam cristo como o "alfa" e o "ómega" (Idem, p. 25). Isso corrobora o sagrado presente na própria constituição 
estrutural dos poemas, como a enfatizar a presença de deus e como um respaldo para filosofar.

O sagrado do núcleo de poemas $O$ silêncio de deus como será desvelado por meio das análises, reside no silêncio de deus e é revelado apenas por meio dele. Corrobora com essa ideia Nejar ao afirmar que "[...] apenas no silêncio conquistado com a palavra vige o mais intenso vigor, a energia da luz” (In: GASTÃO, 2003, p. 9-10).

A luz é a presença de deus, da fé que ilumina a escuridão que atravessa as buscas inconstantes por deus, haja vista a relação de ausência e mudez reiterada ao longo dos versos dos poemas. Isso posto, há na poesia de Ana Marques Gastão, especialmente, "uma convergência com conhecidos textos místicos que acentuam a ideia de que o sentido do absoluto é apenas apreensível pela linguagem do silêncio" (RIBEIRO, 2008, p. 25). Palavra e silêncio ajudam a poeta a filosofar sobre deus, pois ela mesma defende que "o poeta [...] não é filósofo, mas filosofa" (GASTÃO, 2013, p. 21).

Octavio Paz, em $O$ arco e a lira, pontua que "a poesia é [...] exercício espiritual [...]. Súplica ao vazio, diálogo com a ausência [...] Oração, litania, epifania, presença. (PAZ, 1982, p. 15). A poesia de Ana Marques Gastão nos liga ao sagrado por conter, como dissemos anteriormente, uma filosofia sobre deus em seus versos. Para tanto, iniciemos as análises dos poemas selecionados.

\section{O sagrado no silêncio de deus}

Ao longo dos versos de $O$ silêncio de deus, podemos observar que as palavras constroem afirmações que constituem o campo semântico do silêncio: "O silêncio de deus", "deus emudeceu", "perda de deus", "deus, água no labirinto", "deus sem rosto”, "deus, feto do cansaço". Tais expressões reiteram a mudez e a ausência de deus, enquanto o eu lírico continua sua busca por deus. O primeiro poema já nos revela a existência de um deus, em letra minúscula.

O aparecimento de deus grafado em minúscula pode ser entendido como uma tentativa de retirar dele uma carga teológica institucionalizada e potencializar em deus o sagrado que o divino possui em todas as manifestações do sagrado. Nelson Oliveira atesta isso ao salientar que os poetas portugueses atuais "[...] estão dizendo por meio de seus poemas que as ferramentas tradicionalmente usadas pela religião não são as melhores para o problema do sagrado" (OLIVEIRA, 2009, p. 221), o que ocasiona uma redefinição da face do sagrado (Idem, 222). Isso possibilita fazer uma religação com o sagrado, uma vez que este "[...] transcende este mundo, que aqui se manifesta” (ELIADE, 2010, p. 164).

Segue o poema:

A

Na breve alegria

ou em seu início

há um deus, senão

no fim da tragédia.

(GASTÃO, 2003, p. 44)

A alegria é tão fugaz, e a tristeza facilmente sobrepõe-se a ela. Ainda que seja breve a alegria ou permanente a tragédia - indicando o fim, que podemos ler como a permanência da tristeza - há um deus. Há a afirmação de sua presença nesses versos, como a indicar que 
a busca não é imprecisa ou sem sentido, mas uma constatação de que deus está situado entre sentimentos duais.

No segundo poema, o sentimento de tristeza é retomado, e o verso que intitula a coletânea aparece para introduzir a condição recorrentemente afirmada ao longo dos poemas da permanência do silêncio indestrutível de deus contra a qual não se encontra modo de combater.

B

Mesmo na tristeza

rege a geometria

a que conduz e ordena

o silêncio de deus.

(GASTÃO, 2003, p. 45)

Ainda que haja tristeza, a geometria "conduz e ordena / o silêncio de deus". A palavra geometria nos remete a espaço, o que podemos compreender no poema como a existência de um espaço específico onde o silêncio de deus é conduzido e ordenado. Ora, o eu lírico habita um mundo. Nesse sentido, é este o espaço em que se instala e se evidencia o silêncio de deus, no mundo, entre os homens que o habitam.

O próximo poema nos mostra que o sentido de deus é captado em meio ao seu silêncio. Nele, deparamo-nos com o inefável, pois o silêncio faz parte de todas as linguagens humanas, mas é essencial na linguagem do espírito, de deus, cujo sentido é apenas alcançado pela linguagem do silêncio. A poeta joga com a ideia de que o mundo racional impede a religação com deus:

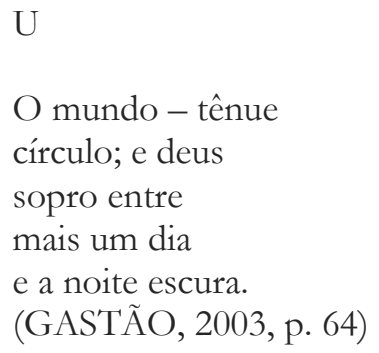

Alguns dos poemas da coletânea $O$ silêncio de deus funcionam como aforismos - inerentes à filosofia, mas que funcionam com a literatura - por constituírem uma sentença poética breve que exprime um pensamento relacionado a deus e na medida em que contribuem para a construção de uma filosofia poética sobre ele. Vejamos o poema "U”. Sua constituição poética nos traz a definição de mundo como um "tênue círculo", remetendo-nos à fugacidade das coisas cotidianas que são repetidas a cada novo dia como um ciclo de vida em que tudo acontece de igual maneira. Ou, em significado adverso, podemos ler como a construção esférica da terra que comporta esse mundo em sua rotação fugaz e sempre em formato circular. Ou, até mesmo, em grau mais perto do sagrado, o tênue círculo que é o mundo se liga à representatividade da eternidade, da perfeição e da divindade, uma vez que não tem princípio nem fim. Reside nesta última leitura uma proximidade do mundo com deus. Por isso, adiante lemos os versos: "e deus / sopro entre / mais um dia / e a noite escura", que corroboram o entendimento de que deus habita o mundo, e seu silêncio é apreensível pelo eu lírico no mundo que é regido por uma temporalidade em que deus se 
presentifica como um sopro, que "tem, universalmente, o sentido de um princípio de vida" (CHEVALIER; GHEERBRANT, 1998, p. 850), entre um dia claro e uma noite escura.

A mudez e ausência de deus é reiterada nos seguintes poemas:

C

Morrer por nada

ter alcançado

e morrer exausto

porque deus emudeceu

em nosso diálogo

extremo e irrazoável.

(GASTÃO, 2003, p. 46)

Mircea Eliade escreve que "toda crise existencial põe de novo em questão, ao mesmo tempo, a realidade do Mundo e a presença do homem no Mundo [...], é a experiência do sagrado que funda o mundo" (ELIADE, 2010, p. 171). No poema que agora se inscreve, temos um eu lírico que reflete sobre sua condição humana mortal no mundo. O que se evidencia é que ele morre duas vezes: a primeira, por não ter obtido sucesso, "por nada ter alcançado"; a segunda, por exaustão diante da tentativa insistente de estabelecer um diálogo com deus, mas um deus que emudeceu. Há aqui a crise existencial de um eu lírico situado no mundo que busca estabelecer um contato com deus, o que se configura como a experiência do sagrado, como afirma Eliade. O sagrado é justamente o que se busca ao divisar a existência de um mundo profano. Busca-se deus, mas a sua mudez é motivo de angústia para o eu lírico. O diálogo travado entre os dois é ainda "extremo e irrazoável" na medida em que o eu lírico é intenso em suas tentativas que, por vezes, fogem da razão, já que só recebe silêncio. Por isso mesmo, como lemos nos versos do poema "E":

\section{Toda a lucidez}

é consciência

da perda de deus.

(GASTÃO, 2003, p. 48)

No entanto, ainda que a procura seja imprecisa, o eu lírico mostra-se ciente da presença da luz no mundo, afirmando o poder absoluto de deus, como vermos no poema "I":

No incurável mundo

só deus é.

Ó cépticos místicos!

Ó místicos cépticos!

(GASTÃO, 2003, p. 52)

Há a presença de deus na ausência. Ao contrário da descrença e do desinteresse que o silêncio poderia provocar, surge a nostalgia melancólica:

$\mathrm{P}$

Melancolia

https://periodicos.unifap.br/index.php/letras

Macapá, v. 8, n. 3, $2^{\circ}$ sem., 2018 
O deus dos poemas de Ana Marques Gastão é palavra, como também silêncio. Além disso, é ainda refúgio para o qual o eu lírico se orienta:

M

Noite dos sentidos

ao espírito, és

morada onde

às vezes esqueço

o cinzento dia.

(GASTÃO, 2003, p. 56)

Neste poema, a atmosfera da noite permite o aguçamento das percepções sensoriais do eu lírico. Os sentidos tornam-se o fio condutor, o meio que possibilita o estabelecimento de uma ligação com o espírito. Aqui, a palavra deus é substituída por espírito, mas fica claro que é apenas outro termo para se remeter a deus. E o eu lírico, exaurido, a ele se dirige e revela: "és morada". O espírito é refúgio, que propicia o esquecimento de um "cinzento dia". Em outro poema, o silêncio de deus é compreendido como sustentação em meio a dor:

Q

Antevi a morte na desolada matéria reconheci a cal nos cadáveres amados.

Deus sem rosto, és regresso porém

o silêncio que na dor me sustém rigor da luz no mundo só mundo.

(GASTÃO, 2003, p. 60)

A morte é um dos temas tratados ao longo dos poemas. Não apenas a morte, mas também a vida, vista de um modo pessimista em virtude dos tormentos, da ausência de diálogo com deus e da morte, fim último para o qual todos caminham.

No poema, a morte é previamente vista na "desolada matéria" dos "cadáveres amados", que podemos entender como uma visão do destino das pessoas amadas do eu lírico. Este que se volta para deus no momento em que é assolado pela dor, ainda que seja um "Deus sem rosto" para o qual ele regressa, buscando sustentação em seu silêncio porque só deus é o "rigor da luz no mundo só mundo".

A coletânea termina com o poema " $Z$ " no qual o eu lírico se refere a um Tu, com pronome pessoal grafado em maiúscula, em oposição aos outros poemas nos quais o vocábulo "deus" aparece escrito com inicial minúscula. Tal configuração vocabular constitui uma trajetória no interior das composições d'O silêncio de deus, uma vez que nos primeiros poemas há um deus que permanece em silêncio, ausente, embora pressinta-se sua presença, mudo, que não tece diálogos, para desembocarmos no último poema no qual há um Tu que é princípio e fim. Segue o poema: 
No princípio eras Tu, no fim Tu serás e no meio dormem os homens um longo, longo sono onde o tormento se faz carne e habita entre nós. Porque ninguém jamais Te viu. Outros virão, outros, outros e outros para consumar a círculo da vida, os que chegam depois de Ti e nunca antes, ou não fosses Tu o princípio, ordem e silêncio de todas as coisas.

No princípio eras Tu, no fim Tu serás e no meio conhecem os homens a dor e a devastação, a fome e a ruína, a solidão e a injustiça. Porque ninguém jamais Te viu. Nem os que choram, nem os que riem nem os aflitos, nem os doentes, nem os que envelhecem nem os que, fatigados, morrem.

Eloi, Eloi

quem te ama chora.

No princípio eras Tu, no fim Tu serás.

(GASTÃO, 2003, p. 67)

Este poema é uma glosa que tem como mote um versículo retomado do Apocalipse nos versos: "No princípio eras Tu, no fim Tu serás". No livro do Apocalipse de São João, consta o seguinte trecho:

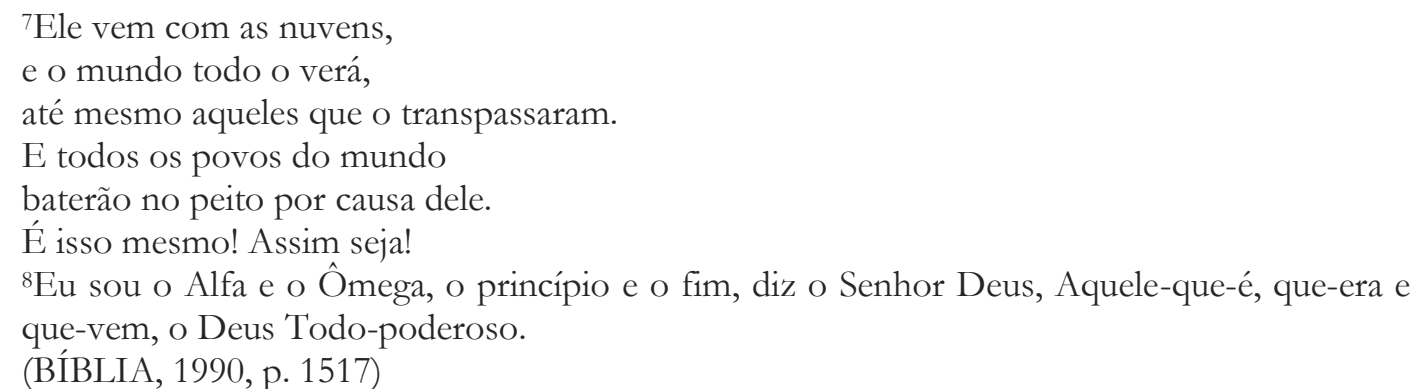

A primazia é dada a um trecho do citado versículo constituído pelas palavras "princípio e fim" que no poema se convertem no destaque dado ao Tu: "No princípio eras Tu, no fim Tu serás", constituindo anaforicamente a entrada das duas primeiras estrofes e da última. Ao que tudo indica, o Tu se refere a um Deus superior, início e fim de tudo, que há de retornar para este mundo e viverá entre os homens. Outra indicação que serve como comprovação deste fato são as repetições da palavra hebraica Eloi no poema. No Evangelho segundo são Marcos, consta o significado desta palavra que foi proferida por Jesus Cristo no momento de sua crucificação, conforme os versículos 33-34 do capítulo 15 mostram:

${ }^{33}$ Ao chegar o meio-dia, até às três horas da tarde, houve escuridão sobre toda a terra. ${ }^{34}$ Pelas três horas da tarde, Jesus deu um forte grito: "Eloi, Eloi, lamá sabactâni??", que quer dizer: "Meu Deus, meu Deus, por que me abandonaste?”. (BÍBLIA, 1990, p. 1246).

Eloi significa, portanto, Deus. É o Deus cujo pronome pessoal Tu está grafado em 
maiúscula para comprovar sua onipotência quando o eu lírico Lhe faz referência. No entanto, entre o princípio e o fim estão os homens. Situados no meio do Tu que é "princípio, ordem e silêncio de todas as coisas". Os homens do mundo dormem "um longo, / longo sono" porque esperam por um Tu enquanto "o tormento se faz carne / e habita entre nós" porque, nas palavras do eu lírico, "ninguém jamais

Te viu". Ainda assim, outros homens virão para que o círculo da vida possa continuar enquanto todos esperam. $\mathrm{Na}$ mesma medida, também conhecem os homens "a for e a devastação, a fome e a ruína, a solidão e a injustiça", e o motivo disso é reafirmado: "Porque ninguém jamais Te viu", nem mesmo "os que choram, nem os que riem / nem os aflitos, nem os doentes, nem os que / envelhecem nem os que, fatigados, morrem". Nem mesmo esses, foram dignos de ver Eloi. Por isso, o amor de Eloi é um amor que causa sofrimento, como acusam os veros: "Eloi, Eloi / quem te ama chora.". Em seguida, o poema termina com os versos iniciais: "No princípio era Tu, no fim Tu serás".

Como é possível observar pela leitura do poema " $Z$ ", há um certo pessimismo que faz o eu lírico reconhecer o Tu, princípio e fim, como causador de todas as tormentas e agruras pelas quais os homens passam no mundo porque ninguém jamais $\mathrm{O}$ viu. Por esse motivo, os homens permanecem inseridos nessas circunstâncias e outros ainda virão para "consumar o círculo da vida", mas que chegam depois dEle, jamais antes porque é Ele que ordena tudo e todas as coisas. Além disso, a frase "Eloi quem te ama chora" é reveladora de uma angústia diante de um amor que causa sofrimento. Logo, há uma atmosfera de negatividade que perpassa o citado poema, pois até mesmo os mais amargurados não puderam vê-Lo e continuarão à mercê de tudo isso até que o fim os livre porque, finalmente, Ele será.

As referências teológicas cristãs no poema "Z" - de que Cristo é o alfa e o ômega, Deus é onipresente, e, ao longo dos poemas, de que o sagrado está no silêncio e a palavra contém o germe do silêncio -, embora limitadoras para a poeta, são o ponto de partida para ampliar, potencializar o sentido de deus, com inicial minúscula, e continuar em sua procura, e não de Deus, com inicial maiúscula, uma vez que Este aparece com uma construção teológica limitadora.

\section{Considerações finais}

Nelson Oliveira, na obra Axis mundi: o jogo de forças na lírica portuguesa contemporânea, ressalta que a poesia revela-se como a forma mais poderosa de experiência mística atualmente e que os poetas estão redefinindo as faces do sagrado ao mesmo tempo em que redefinem a si mesmos e à sociedade (OLIVEIRA, 2009, p. 222-223). O sagrado está presente na poesia da portuguesa Ana Marques Gastão, como bem pudemos contemplar na leitura feita da coletânea $O$ silêncio de deus, sendo redefinido pelo modo como a poeta trata de deus, ou seja, sem a institucionalização teológica contida nas religiões, mas como uma reflexão filosófica que tem origem no silêncio de deus.

\section{Referências}

BÍBLIA. Português. Bíblia sagrada. Edição pastoral. Tradução de Ivo Storniolo e Euclides Martins Balancin. São Paulo: Paulus, 1990. 1584 p.

CHEVALIER, Jean; GHEERBRANT, Alain. Dicionário de Símbolos. Tradução Vera da Costa e Silva. Rio de Janeiro: José Olympio, 1998.

ELIADE, Mircea. O sagrado e o profano: a essência das religiões. Tradução Rogério 
Fernandes. 3. ${ }^{a}$ ed. São Paulo: Editora WMF Martins Fontes, 2010.

GASTÃO, Ana Marques. O silêncio de deus (2001). In: . A definição da noite. São Paulo: Escrituras Editora, 2003, p. 43-67.

As palavras fracturadas; ensaios. Lisboa: Theya, 2013.

NEJAR, Carlos. A invencível noite. In: GASTÃO, Ana Marques. A Definição da noite. São Paulo: Escrituras, 2003.

OLIVEIRA, Nelson de. Axis mundi: o jogo de forças na lírica portuguesa contemporânea. São Paulo: Ateliê Editorial, 2009.

PAZ, Octavio. O arco e a lira. Tradução de Olga Savary. Rio de Janeiro: Nova Fronteira, 1982.

RIBEIRO, Manuel António. Não invocar em vão o nome de Deus. Viragem, n ${ }^{\circ}$, Jan/Abr 2008, p. 25-27. Disponível em: < http://www.metanoia-mcp.org/viragem/viragem 30 59/viragem58.pdf>. Acesso em: 11 ago. 2018. 